\title{
Role of pulmonary intravascular macrophages in endotoxin-induced lung inflammation and mortality in a rat model Sukhjit S Gill ${ }^{\dagger 1}$, Sarabjeet S Suri ${ }^{\dagger 1}$, Kyathanahalli S Janardhan ${ }^{1}$, Sarah Caldwell1 ${ }^{1}$ Tanya Duke ${ }^{1,2}$ and Baljit Singh*1
}

\author{
Address: ${ }^{1}$ Department of Veterinary Biomedical Sciences, University of Saskatchewan, Saskatoon, SK S7N5B4, Canada and ${ }^{2}$ Department of Small \\ Animal Clinical Sciences, University of Saskatchewan, Saskatoon, SK S7N5B4, Canada \\ Email: Sukhjit S Gill - sukhjeet_gill@hotmail.com; Sarabjeet S Suri - sarabjeet.singh@usask.ca; Kyathanahalli S Janardhan - kjanardh@ksu.edu; \\ Sarah Caldwell - sarah.caldwell@usask.ca; Tanya Duke - tanya.duke@usask.ca; Baljit Singh* - baljit.singh@usask.ca \\ * Corresponding author †Equal contributors
}

Published: 24 October 2008

Respiratory Research 2008, 9:69 doi:10.1186/1465-9921-9-69

This article is available from: http://respiratory-research.com/content/9/1/69

(c) 2008 Gill et al; licensee BioMed Central Ltd.

This is an Open Access article distributed under the terms of the Creative Commons Attribution License (http://creativecommons.org/licenses/by/2.0), which permits unrestricted use, distribution, and reproduction in any medium, provided the original work is properly cited.
Received: 10 August 2008

Accepted: 24 October 2008

\begin{abstract}
Background: Bile-duct ligated (BDL) rats recruit pulmonary intravascular macrophages (PIMs) and are highly susceptible to endotoxin-induced mortality. The mechanisms of this enhanced susceptibility and mortality in BDL rats, which are used as a model of hepato-pulmonary syndrome, remain unknown. We tested a hypothesis that recruited PIMs promote endotoxin-induced mortality in a rat model.
\end{abstract}

Methods: Rats were subjected to BDL to induce PIM recruitment followed by treatment with gadolinium chloride (GC) to deplete PIMs. Normal and BDL rats were treated intravenously with E. coli lipopolysaccharide (LPS) with or without GC pre-treatment followed by collection and analyses of lungs for histopathology, electron microscopy and cytokine quantification.

Results: BDL rats recruited PIMs without any change in the expression of IL-I $\beta$, TNF- $\alpha$ and IL-I0. GC caused reduction in PIMs at 48 hours post-treatment $(P<0.05)$. BDL rats treated intravenously with $E$. coli LPS died within 3 hours of the challenge while the normal LPS-treated rats were euthanized at 6 hours after the LPS treatment. GC treatment of rats 6 hours or 48 hours before LPS challenge resulted in $80 \%(\mathrm{I} / 5)$ and $100 \%(0 / 5)$ survival, respectively, at 6 hours post-LPS treatment. Lungs from BDL+LPS rats showed large areas of perivascular hemorrhages compared to those pre-treated with GC. Concentrations of IL-I $\beta$, TNF- $\alpha$ and IL-I0 were increased in lungs of BDL+LPS rats compared to BDL rats treated with GC 48 hours but not 6 hours before LPS (P $<0.05)$.

Conclusion: We conclude that PIMs increase susceptibility for LPS-induced lung injury and mortality in this model, which is blocked by a reduction in their numbers or their inactivation.

\section{Background}

Bile duct ligated (BDL) rats show biliary cirrhosis and are used as a model to study hepato-pulmonary syndrome which occurs in 10-15\% of human patients with cirrhosis and portal hypertension, has no treatment and causes significant mortality $[1,2]$. BDL rats have increased vascular translocation of Gram negative bacteria, increased blood levels of TNF- $\alpha$, endothelin-1 and endotoxins as well as 
recruitment of PIMs $[3,4]$. PIMs have been linked to an increase in TNF- $\alpha$ expression and iNOS activity in BDL rats $[2,3]$. Although a relationship between PIMs and sensitivity of BDL rats to endotoxin-induced mortality has been speculated [5], a direct link between the two is yet to emerge.

PIMs are unique inflammatory cells, which are normally present in sheep, cattle, goat and horse but not in humans, dogs, rats and mice [6,7]. The species without PIMs, compared to those with PIMs, tolerate large dosages of endotoxin without showing significant pulmonary vascular responses, inflammation and edema [8-11]. The PIMs are credited with removal of majority of bloodborne endotoxins and bacteria even following injection in hepatic portal vein [12]. We and others have shown that removal of PIMs with gadolinium chloride or clodronate inhibits endotoxin-induced lung inflammation[13,14]. Interestingly, PIM recruitment is observed in species normally devoid of these cells under experimental physiological stresses such as liver injury induced by chronic BDL and intraperitoneal infection with $E$. coli $[5,15,16]$. Although the biology of recruited PIMs is poorly understood, PIM recruitment may increase host susceptibility for lung inflammation [15].

The role of recruited PIMs in endotoxin-induced inflammation in BDL rats, which are used as a model for hepatopulmonary syndrome, is largely obscure. Therefore, we investigated the biology of PIMs in BDL rats with an aim to determine if PIM depletion protects against endotoxininduced mortality and lung inflammation. The experimental data show that BDL induces recruitment of PIMs and their depletion or inactivation protects BDL rats from E. coli LPS induced lung inflammation and mortality.

\section{Materials and methods \\ Animals}

The experimental protocols were approved by the University Protocol Review Committee on Animal Care and Supply, and experiments were conducted according to the Canadian Council on Animal Care Guidelines. Specific pathogen free 350-400 gram male Sprague-Dawley rats were procured from Charles River Laboratories, Canada. Rats were acclimatized for a period of one week before the experiment.

\section{Experiment I}

BDL was performed on rats as previously described $[1,5]$. Briefly, rats were anesthetized by intraperitoneal administration of xylazine $(20 \mathrm{mg} / \mathrm{kg}$ ) and ketamine $(100 \mathrm{mg} / \mathrm{kg})$. A mid line incision was made, the common bile duct was identified and ligated at two points $5 \mathrm{~mm}$ apart and resected in between the two ligatures $(N=10)$. In sham operated animals $(\mathrm{N}=4)$, the common bile duct was identified and separated from the surrounding soft tissue without ligation and resection. After recovery from anesthesia, rats had free access to water and rat chow. After 4 weeks, five of the BDL rats were treated with gadolinium chloride (GC;10 mg/kg tail vein) and remaining five were used as BDL controls. The rats were euthanized 48 hours after the GC treatment under xylazine-ketamine anesthesia and cardiac exsanguation. Five rats were euthanized without any surgery or treatment.

\section{Experiment 2}

Control and BDL ( 4 weeks after the surgery) rats $(n=6$ / group) were administered $E$. coli lipopolysaccharide (LPS) intravenously $(0.1 \mathrm{mg} / \mathrm{kg}$ iv $)$. In another group, $10 \mathrm{BDL}$ rats were administered GC (10 mg/kg i.v) and were challenged with $E$. coli LPS either 6 hours $(\mathrm{N}=5)$ or 48 hours $(n=5)$ after GC treatment. All animals were euthanized 6 hours after the LPS treatment.

\section{Lung tissue collection and processing}

Lungs were collected as previously described [15]. The right bronchus was ligated followed by right lung removal and freezing in liquid nitrogen. The left lung was instilled with $2 \%$ paraformaldehyde with $0.1 \%$ glutaraldehyde under $20 \mathrm{~cm}$ water pressure and ligated at the level of the trachea to prevent backflow. The ligated left lung was removed and fixed in 4\% paraformaldehyde for 24 hours. Following fixation, the lung was cut into several pieces of $3 \mathrm{~mm}$ thickness. From each lung, pieces numbered 2, 4 and 6 were collected for light microscopy. Tissues collected for light microscopy were processed and embedded in paraffin. Sections (five micron) were cut onto the polyL-Lysine coated slides and used for hematoxylin and eosin staining and immunostaining.

Pieces of the left lung were fixed in $2 \%$ paraformaldehyde containing $0.1 \%$ glutaraldehyde for 3 hours at $4^{\circ} \mathrm{C}$ and processed for embedding in LR White followed by polymerization under ultraviolet light for immuno-electron microscopy. One micron sections were prepared and stained with toluidine blue to select appropriate areas for preparation of thin $(100 \mathrm{~nm})$ sections, which were placed on nickel grids.

\section{Immunohistochemistry for monocytes/macrophages}

Immunohistochemical methods have been described previously [15]. Briefly, lung sections from all the rats in each of the groups were deparaffinized and rehydrated followed by quenching of endogenous peroxidase. Sections were treated with pepsin $(2 \mathrm{mg} / \mathrm{ml} 0.01 \mathrm{~N}$ hydrochloric acid) to unmask antigens, to $1 \%$ bovine serum albumin to block non-specific sites and to primary anti-macrophage ED-1 antibody (1:100) for 60 minutes followed by appropriate horseradish peroxidase-conjugated secondary antibody (1:100) for 30 minutes. The color was developed 
with a commercial kit (Vector Laboratories, Canada). The staining controls included incubation of sections with only secondary antibody, isotype matched antibodies or with only color development reagents. Another control was to stain some of the sections with anti-von Willebrand Factor (vWF) antibody (1:200), which recognizes vascular endothelium. Finally, sections were counterstained with methyl green.

\section{Quantification of ED-I positive cells}

The methods have been described previously [15]. An observer, who was blinded to the identity of treatment groups, counted the ED-1 positive cells in alveolar septa. The observer obtained counts of septal cells stained with ED-1 antibody from 10 fields at X100 in lung sections from all the rats used in the experiments.

\section{Immuno-gold electronmicroscopy}

Immuno-gold electron microscopy methods have been described elsewhere [15]. Briefly, the sections were blocked with $1 \%$ bovine serum albumin and $0.1 \%$ Tween20 in tris-buffered saline; $\mathrm{pH} 7.9$ for 30 minutes followed by incubation with primary (ED-1, TNF- $\alpha$, IL- $1 \beta$ and IL10) antibodies for one hour and appropriate gold conjugated secondary antibodies for one hour. The sections were stained with $2 \%$ aqueous uranyal acetate and then lead citrate.

\section{Reverse transcriptase-polymerase chain reaction}

Total RNA was extracted from lungs of three rats from each group tissues of rat by sequential extraction with TRIzol reagent (Invitrogen, ON, Canada) followed by treatment with RNase-free DNase (Qiagen, ON, Canada) and purification on RNeasy mini columns (Qiagen) according to the manufacturer's instructions. Integrity of RNA was confirmed by agarose gel electrophoresis and RNA was quantified by spectrophotometric analysis. Superscript III one-step RT-PCR system with Platinum Taq DNA polymerase (Invitrogen) was used to detect expression of IL-1 $\beta$ : 5'-TTGCCCGTGGAGCTTC-3' 5'-CGGGTTCCATGGTG AAC-3'), TNF- $\alpha$ : 5'-GCACAGAAAGCATGATCC-3' 5'-GTGGGTGAGGAGCACAT-3') and IL-10 (5'-GCTGCGACGCTGTCAT-3' 5'-GCGCTGAG CTGTTGCT-3') in lung tissues from various treatments. Reactions were performed as directed by the manufacturer. Each reaction was performed using $10 \mathrm{ng}$ of total RNA and thermocycler was programmed for reverse-transcription at $55^{\circ} \mathrm{C}$ for $30 \mathrm{~min}$, initial denaturation of the cDNA at $94^{\circ} \mathrm{C}$ for $2 \mathrm{~min}, 30$ amplification cycles, each of which consisted of $94^{\circ} \mathrm{C}$ for $15 \mathrm{sec}, 59^{\circ} \mathrm{C}$ for $30 \mathrm{sec}$, and $68^{\circ} \mathrm{C}$ for $1 \mathrm{~min}$ followed by a final extension at $68^{\circ} \mathrm{C}$ for $5 \mathrm{~min}$. To ensure lack of DNA contamination 2 units of Platinum Taq DNA polymerase was substituted for the Superscript III RT/Platinum Taq mixture in the reaction. A negative control reaction consisted of all the components of the reaction mixture except
RNA. Amplified PCR products were electrophoresed on a $1 \%$ TAE-agarose gel, stained with ethidium bromide and photographed under UV light.

\section{Myeloperoxidase assay}

Myeloperoxidase (MPO) assay was performed on lung tissues from three rats from each group as described previously [17]. Briefly, Lung tissues were homogenized in 50 $\mathrm{mM}$ Hepes ( $\mathrm{pH} 8.0$ ) containing 0.5\% CTAC and cell-free extract was stored at $-20^{\circ} \mathrm{C}$ till further use. Samples were diluted in phosphate citrate buffer ( $\mathrm{pH}$ 5.0). To the $75 \mu \mathrm{l}$ sample, equal volume of the substrate $(977.5 \mu \mathrm{l} / \mathrm{mL}$ of $\mathrm{TMB}, 20.0 \mu \mathrm{l} / \mathrm{mL}$ of $6 \mathrm{mM}$ Resorcinol and $2.5 \mu \mathrm{l} / \mathrm{mL}$ of $3 \% \mathrm{H}_{2} \mathrm{O}_{2}$ ) was added and after 2 minutes, the reaction was stopped by adding $150 \mu \mathrm{l}$ of stop solution ( $1 \mathrm{M}$ $\left.\mathrm{H}_{2} \mathrm{SO}_{4}\right)$. For zero minutes, $75 \mu \mathrm{l}$ of sample was added to $150 \mu \mathrm{l}$ of cold stop solution containing $75 \mu \mathrm{l}$ of substrate. Microplate was read at $450 \mathrm{~nm}$ and the change in $\mathrm{OD} / \mathrm{min}$ was calculated.

\section{Enzyme-linked immunosorbent assay}

For enzyme-linked immunosorbent assay (ELISA), frozen lung tissues from three rats from each group were homogenized in HBSS solution containing protease inhibitor cocktail and centrifuged at $4^{\circ} \mathrm{C}$ for 20 minutes at $15000 \mathrm{~g}$. Supernatants were collected and stored at $-80^{\circ} \mathrm{C}$ till further use. Microtitre plates were coated with $50 \mu$ l of capture antibody diluted with sodium phosphate buffer and incubated at $4{ }^{\circ} \mathrm{C}$ overnight. Next day, following wash and incubation with blocking buffer (1\% BSA in PBS) for one hour, wells were washed with PBST (PBS containing 0.05\%Tween-20). Standards and samples (100:l; diluted in PBST containing 1\% BSA) were added to the wells and plate was incubated at $37^{\circ} \mathrm{C}$ for 2 hours. After removing standards and samples, wells were washed with PBST and detection antibody (100:1; diluted in PBS containing 1\% BSA) was added. Plates were incubated at $37^{\circ} \mathrm{C}$ for one hour. After washing wells with PBST, streptavidin-HRP (100:l; 1:2500 in PBS containing 1\% BSA) was added to each well and incubated at room temperature for $30 \mathrm{~min}$ utes. Wells were washed thoroughly with PBST, TMB substrate (100:1) was added and incubated in dark at room temperature for 20 minutes. On color development, reaction was stopped by adding $50: 1$ of $0.5 \mathrm{M}$ sulfuric acid. Microplates were read at $450 \mathrm{~nm}$.

\section{Statistical analysis}

Analysis was done using a statistical software package (SPSS 12.0 for windows). Differences among groups were compared using one-way analysis of variance followed post-hoc group comparisons. Mortality data were compared with Fischer's test. Statistical significance was accepted at $\mathrm{p}<0.05$. 


\section{Results \\ Effect of BDL \\ Response to $B D L$}

Rats became dull and inactive within two days of ligation of their bile ducts. Their food and water intake decreased and all rats lost up to 50-100 grams of weight over one week after the surgery. Although rats started eating and drinking normally and regained their body weights by 4 weeks after BDL, their urine and mucous membranes became progressively icteric. Nearly four weeks post-BDL, a swelling was evident upon palpation in the anterior abdomen of most of the rats as a result of proximal dilatation of ligated bile duct. Sham operated rats continued to grow normally even after surgery.

\section{PIM recruitment}

Histologic examination showed normal lung morphology in control rats (no surgery) and sham-operated rats and increased numbers of mononuclear cells in the alveolar septa (data not shown). Immunohistochemistry with ED1 antibody, which recognizes rat monocytes/macrophages, stained numerous septal monocytes/macrophages in lungs of BDL rats compared to the normal rats (Figures 1A-D). Immuno-electron microscopy confirmed the intravascular location, adherence to endothelium and ED-1 reactivity of septal macrophages (Figure 1E). Once the intravascular location of ED-1 positive cells was determined with immuno-electron microscopy, we counted these cells in lung sections under a light microscope. BDL rats showed more ED-1 positive cells in their alveolar septa compared to control rats $(p=0.002)$. GC treatment of BDL rats depleted ED-1 positive cells $(p=0.05)$ (Figure 2).

Expression of IL-I $\beta$, TNF- $\alpha$ and IL-IO

We detected mRNA for IL-1 $\beta$, TNF- $\alpha$ and IL-10 in lung homogenates from rats from control, BDL and BDL+GC group. There were no differences in protein concentrations of these three cytokines in lungs of rats from three groups (data not shown).

\section{Recruited PIMs, lung inflammation and mortality}

\section{Response to LPS challenge}

Sham-operated rats did not show signs of stress following LPS treatment and were euthanised at 6 hours post-LPS treatment (Table 1). In contrast, all of the BDL rats $(\mathrm{N}=$ 6) upon challenge with LPS became dull and inactive, showed labored breathing, piloerection, defecation and urination before dying within 3 hours of the treatment. Interestingly, all the BDL rats $(\mathrm{N}=5)$ that were treated with GC 48 hours before the LPS challenge survived till 6 hours after the LPS treatment. Furthermore, 4 out of the 5 BDL rats treated with GC 6 hours prior to the LPS challenge survived up to 6 hours post-LPS treatment. The mortality in BDL+LPS group was significantly higher $(\mathrm{P}<$
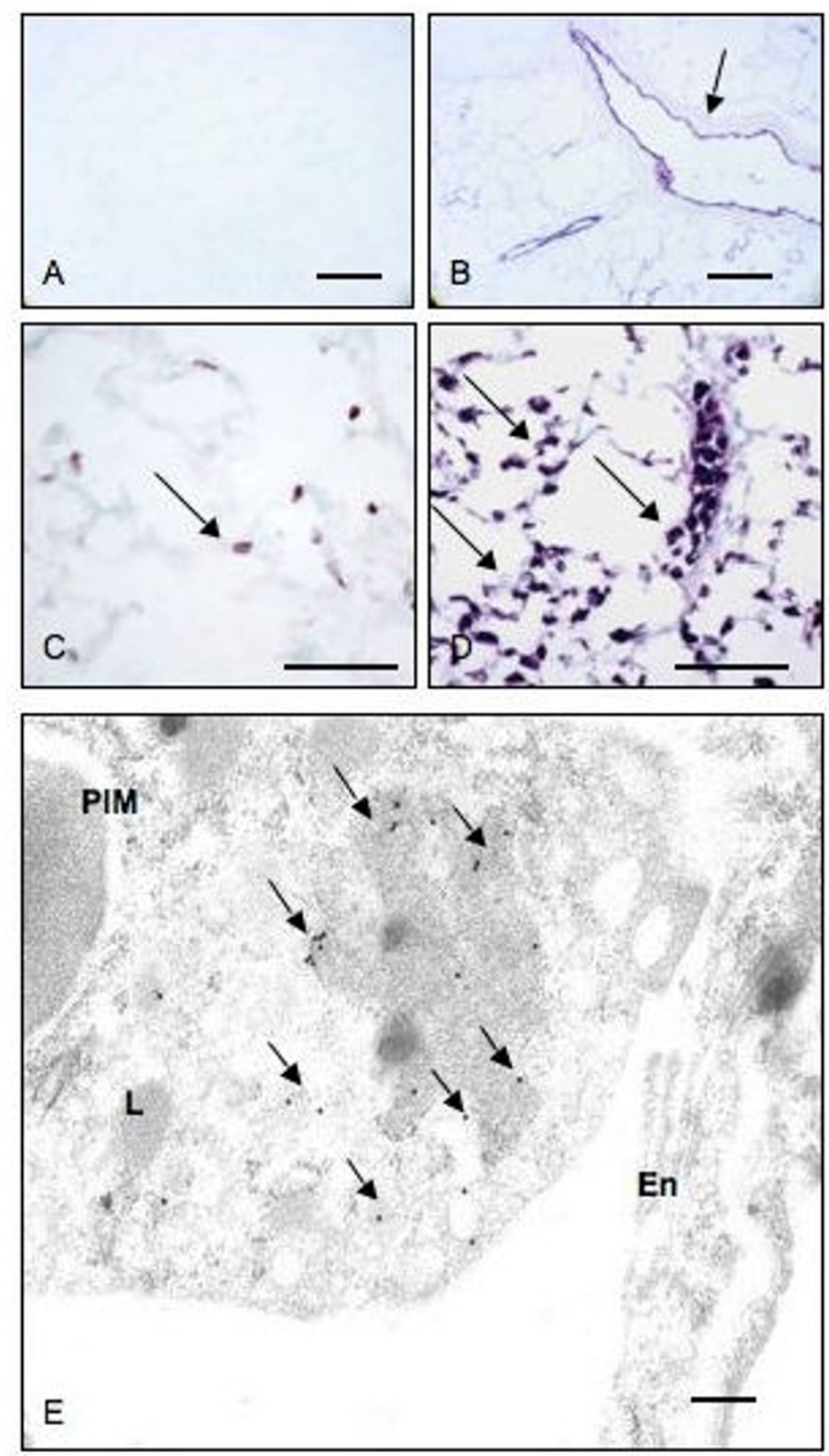

\section{Figure I}

PIM recruitment: Lung section stained with only secondary antibody (A) show no reaction while antivWF antibody stained vascular endothelium (arrow). Lung sections from control rats $(C)$ contained occasional septal EDI-positive cells (arrow) while those from BDL rats had numerous reactive cells in the septa (arrows). Immunoelectron micrograph $(\mathrm{E})$ shows gold labeling (arrows) in the cytoplasm as an indication of ED-I staining in a PIM. En: Endthelium; PIM: pulmonary intravascualr macrophage; L: lysosome. Bar: A-B: $50 \mu \mathrm{m}$; C-D: $100 \mu \mathrm{m}$; E: I $\mu \mathrm{m}$. 


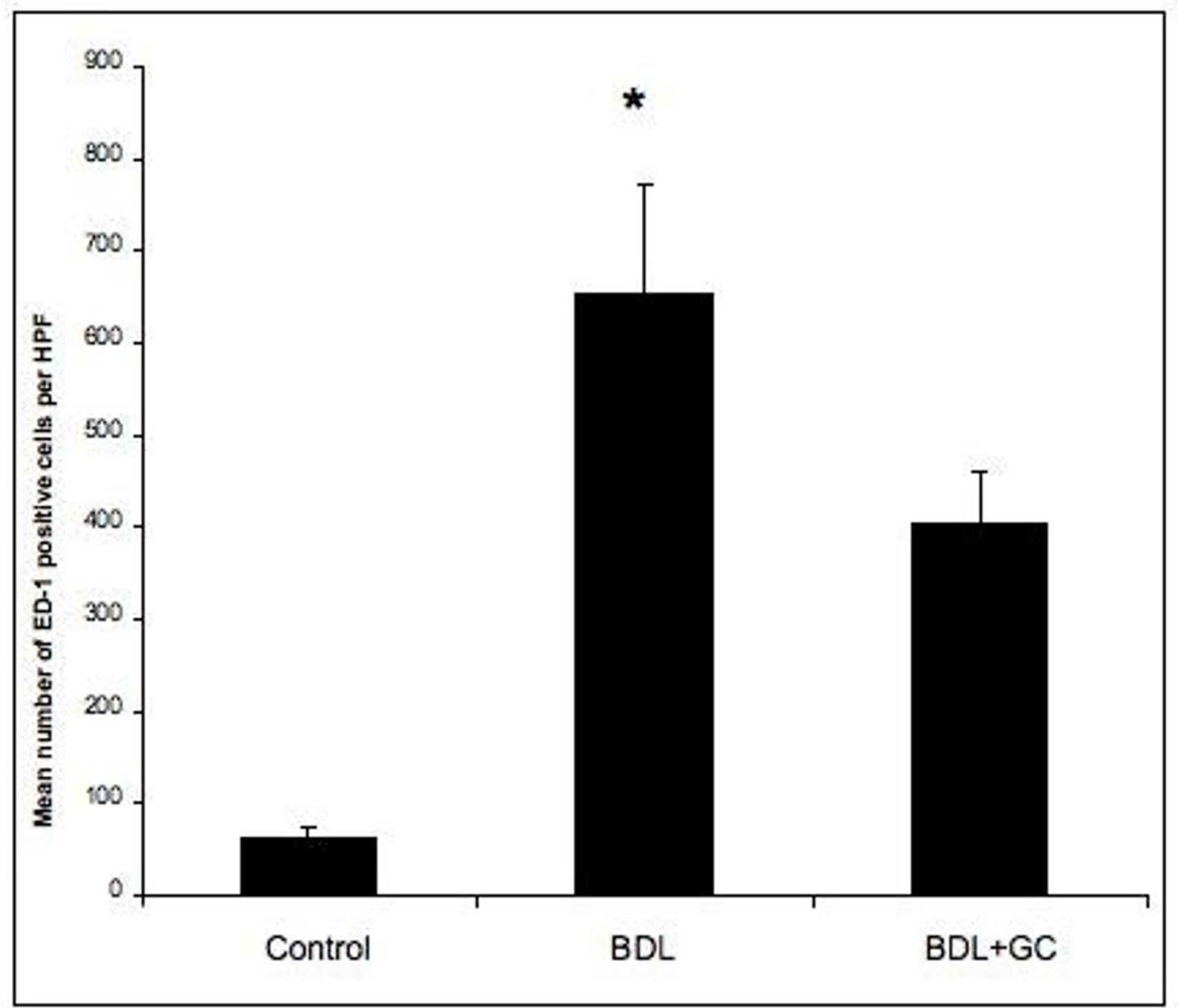

Figure 2

Numerical counts of PIMs: Septal ED-I positive cells showed increase in PIMs in BDL rats compared to the normal rats or at 48 hours after GC treatment of BDL rats (*: $P<0.05$ ).

Table I: Mortality in rats $(*=\mathrm{P}<0.05$ compared to all other groups).

\begin{tabular}{|c|c|c|c|}
\hline \multirow[t]{2}{*}{ Experimental group } & \multirow[t]{2}{*}{ Number of animals } & \multicolumn{2}{|c|}{ Mortality within 6 hrs of LPS challenge } \\
\hline & & Number of rats & $\%$ \\
\hline LPS & $N=5$ & 0 & 0 \\
\hline $\mathrm{BDL}+\mathrm{LPS}$ & $N=6$ & $6^{*}$ & 100 \\
\hline$B D L+G C(6 H)+L P S$ & $N=5$ & I & 20 \\
\hline $\mathrm{BDL}+\mathrm{GC}(48 \mathrm{H})+\mathrm{LPS}$ & $N=5$ & 0 & 0 \\
\hline
\end{tabular}


0.05) compared to all other groups while there were no differences between BDL rats treated with GC before the LPS challenge, the control rats and control rats given only LPS $(P>0.05)$.

\section{Histopathology, neutrophil and PIM recruitment}

We observed perivascular hemorrhages in BDL rats treated with LPS compared to those BDL rats treated with GC prior to LPS treatment (Figure 3). Interestingly, MPO assay showed no differences in neutrophil recruitment in lungs among various treatment groups (data not shown). We found significantly more ED-1 positive cells in BDL+LPS rats compared to all other groups including those BDL rats treated with GC before LPS challenge $(\mathrm{P}<$ 0.05; Figure 4).

\section{Expression of IL-I $\beta$, TNF- $\alpha$ and IL-IO}

BDL rats challenged with LPS had significantly higher concentrations $(\mathrm{P}<0.05)$ of IL-1 $\beta$ (Figure $5 \mathrm{~A})$, TNF- $\alpha$ (Figure 5B) and IL-10 (Figure 5C) in their lungs compared with the control rats, normal rats given only LPS and BDL rats treated with GC 48 hours but not 6 hours before the LPS treatment. Control rats and normal rats treated with LPS had similar lung concentrations of IL-10 (Figure 5C). Immuno-gold electron microscopy showed labeling of PIMs for TNF- $\alpha$ (Figure 6), IL-1 $\beta$ and IL-10 (data not shown).

\section{Discussion}

There is relatively little data on the biology of PIMs compared to other lung macrophages. We have used BDL rats, which recruit PIMs and have been used by others as a model of hepato-pulmonary syndrome, to investigate the role of PIMs in endotoxin-induced mortality and lung inflammation. The data show that PIM depletion as well as inactivation prevents mortality and lung inflammation in LPS-treated BDL rats.

\section{$G C$ reduces the numbers of recruited PIMs in $B D L$ rats}

BDL rats have been used to study the biology of PIMs as well as the mechanisms of hepato-pulmonary syndrome in human patients with liver cirrhosis $[4,5,18,19]$. Similar to previous studies, we also found recruitment of ED-1 positive PIMs in BDL rats. ED-1 antibody binds to a single chain $110 \mathrm{kD}$ glycoprotein expressed in lysosomes of monocytes/macrophages. Due to spatial resolution limits of the light microscope, we used electron microscopy to confirm that ED-1 reactive cells were in septal capillaries, attached to the endothelium and contained lysosomes. Therefore, these cells fulfill ultrastructural and molecular phenotypic criteria for PIMs [6,20]. Recruited PIMs in BDL rats form tighter adhesion with capillary endothelium compared to the transiently recruited PIMs following intraperitoneal E. coli infection [15,16,21]. We observed that GC significantly reduced PIM numbers in BDL rats

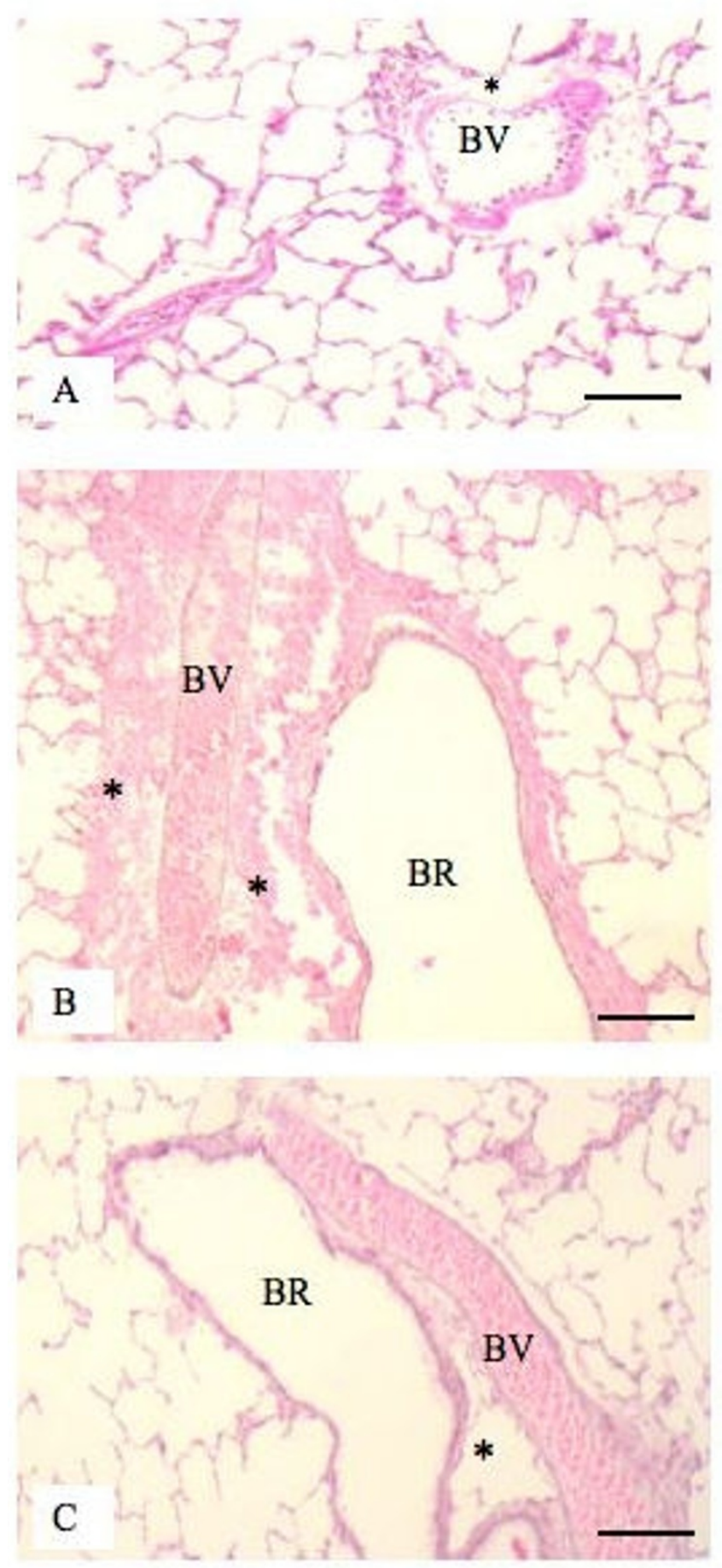

Figure 3

Histopathology of lungs: H\&E staining showed normal histology of lungs from control rats (A) but hemorrhages in perivascular space (*) in lungs of BDL rats treated with LPS (B). Perivascular hemorrhage was absent in lungs of control $(A)$ and $B D L$ rats treated with $G C$ before LPS challenge (C). BR: Bronchiole; BV: Blood vessel. Bar: $100 \mu \mathrm{m}$. 


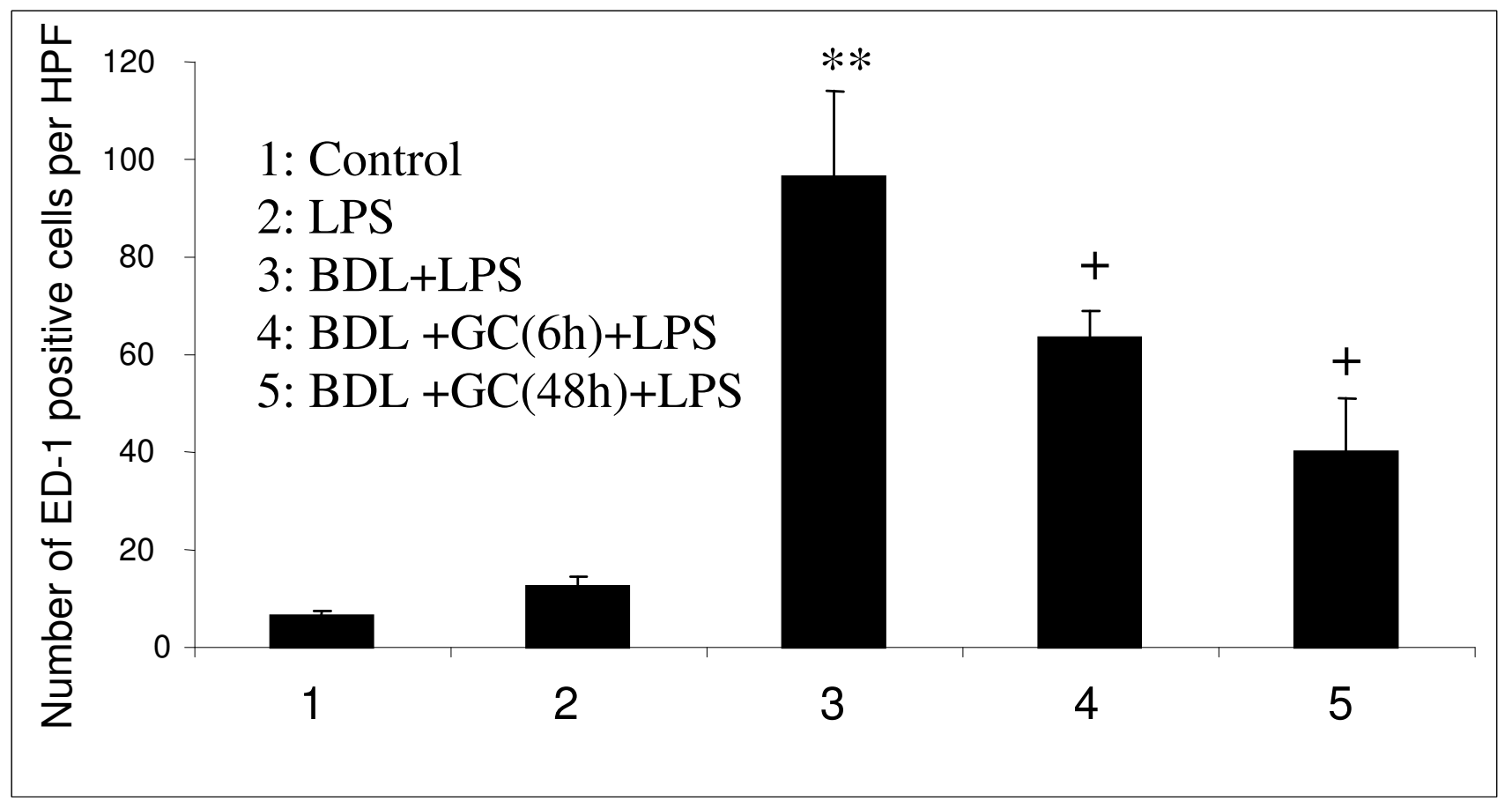

Figure 4

PIM quantification: BDL rats treated with LPS showed more numbers of PIMs (**) compared to all other groups while both GC-treated BDL groups had higher number of PIMs (+) compared to the control and the LPS groups $(P<0.05)$.

without affecting expression of IL-1 $\beta$, TNF- $\alpha$ and IL-10. GC quickly inactivates macrophages before inducing apoptosis in them $[22,23]$ and has been used to remove PIMs in vivo in sheep, cattle and horses and alveolar macrophages in mice and rat, [11,14,24-26]. Interestingly, histologic evaluation showed lack of reduction in macrophages in liver of GC-treated animals. This relative lack of impact of GC on liver cells including macrophages could be due to sequestration of GC, similar to other vascular substances such as endotoxins as shown previously, in PIMs and little availability for liver macrophages in PIMcontaining species [12]. Taken together, these light and electron microscopic data confirm identity of PIMs, and a reduction in their numbers with GC treatment in BDL rats provides us a model to compare host response in BDL rats in the absence or presence of PIMs.

\section{PIM reduction protects against LPS-induced mortality in $B D L$ rats}

We delineated role of PIMs by comparing LPS-induced lung inflammation and mortality in BDL rats and GCtreated BDL rats. The dramatic finding was $100 \%$ and $80 \%$ survival in BDL rats that were treated with GC 48 hours and 6 hours, respectively, prior to the LPS challenge compared to $100 \%$ mortality in LPS-treated BDL rats. In addition to the reduced mortality, there was a reduction in the severity of histological signs of inflammation including recruitment of ED-1 positive cells in the BDL rats treated with GC before the LPS treatment. Although mortality in LPS-treated BDL rats was similar to that previously reported [5], the striking impact of reduction in PIM numbers at 48 hours post-GC treatment on the mortality in BDL rats is novel. The reduced mortality observed in BDL rats treated with GC 6 hours before the LPS challenge is intriguing. In vitro data show that GC rapidly inactivates macrophages before inducing apoptosis in them by 24-48 hours $[22,23]$. Although it is difficult to determine inactivating effects of GC on PIMs in vivo, we speculate that improved survival in the 6 hour group may be due to inactivation of PIMs by the GC. Taken together, the evidence that PIM depletion or inactivation protects against LPS-induced mortality shows PIMs' central role in mortality in this model.

We used the LPS treatment because there is evidence of translocation of endotoxins from the gut of BDL rats, which have been used as a model for hepato-pulmonary syndrome by other investigators $[3,4]$. Endotoxininduced inflammation and shock is characterized by a "cytokine storm" [27]. Macrophages interact with endo- 

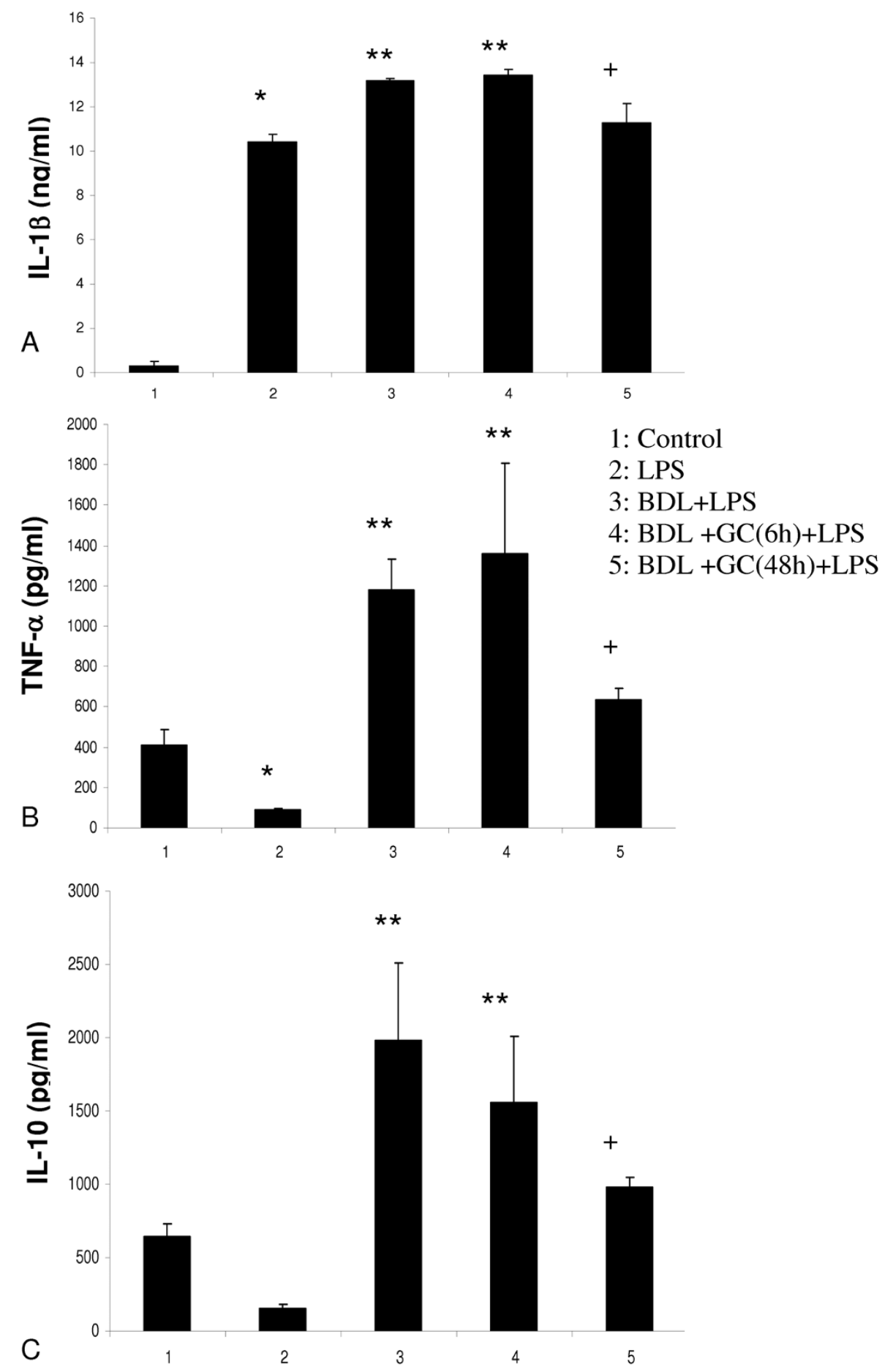

Figure 5

Cytokine expression: IL- I $\beta$ (A) TNF- $\alpha$ (B) and IL- I 0 (C) protein concentrations in lung homogenates of various groups. BDL rats treated with LPS showed higher concentrations $(* *)$ of all the measured cytokines compared to all other groups. + indicates more concentrations than the control and the LPS group while * means more than the control rats. P $<$ 0.05 . 


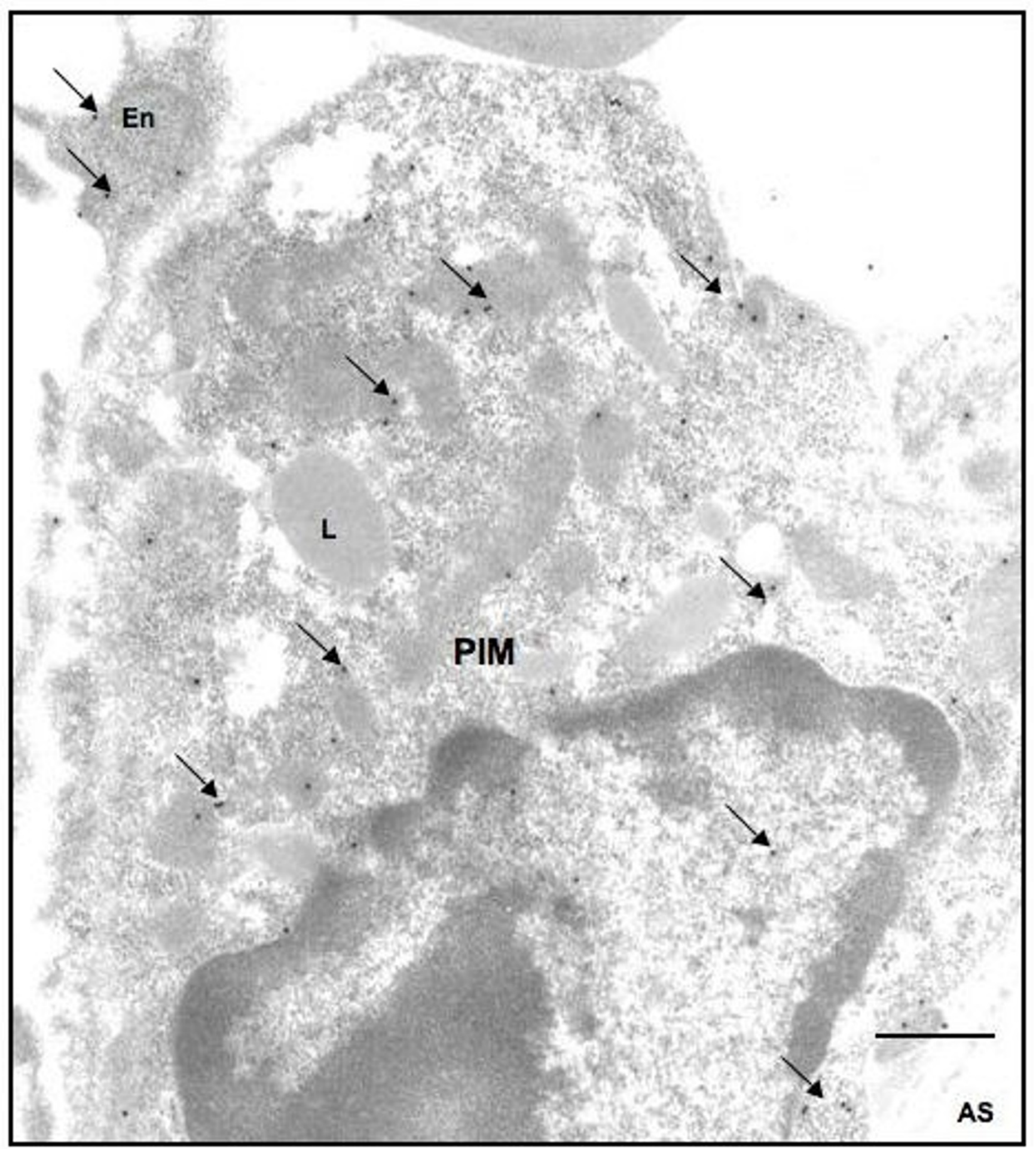

Figure 6

Ultrastructural localization of TNF- $\alpha$ : Immuno-gold electron microscopy showed TNF- $\alpha$ labeling (arrows) in cytoplasm of a pulmonary intravascular macrophage (PIM) and endothelium (En). L: Lysomse; AS: Alveolar space. Bar: I $\mu \mathrm{m}$. 
toxins via Toll-like receptor 4 and are one of the major sources of proinflammatory cytokines in endotoxic shock [28-30]. Therefore, we believe that transient reduction of a major cellular source of multiple cytokines such as a PIM instead of neutralization of a single cytokine in a disease is more beneficial and more rational. The role of recruited PIMs is indirectly highlighted by the recent linkage between susceptibility to diseases such as hepatopulmonary syndrome, for which BDL rats used as a model, and the MCP-1 gene [31]. We observed increased expression of MCP-1 protein in lungs of BDL rats (unpublished data). Even though PIM reduction/inactivation had beneficial effect in LPS-treated BDL rats and in itself is mechanistic, we further examined the lung concentrations of IL$1 \beta$, TNF- $\alpha$ and IL-10. These three inflammatory cytokines play critical roles in endotoxin-induced pathophysiology [32-38] First, we observed ultrastructural localization of IL-1 $\beta$, TNF- $\alpha$ and IL-10 in PIMs in LPS-treated BDL rats. Second, we found a significant reduction in the concentrations of these important and highly relevant cytokines in PIM-depleted LPS-treated BDL rats compared to LPStreated BDL rats, which could be a reason for $100 \%$ survival in these rats. Although mortality was also significantly attenuated in the 6 hour pre-treatment group, there was no reduction in the concentrations of the measured cytokines in lung homogenates. The reasons for this discrepancy between cytokine levels in the lung and reduced mortality are not readily apparent. Based on the GC's previously demonstrated ability to inactivate macrophages, we speculate that GC-induced PIM inactivation may have prevented secretion of these cytokines and resulted in intracellular retention leading to their measurements with ELISA on lung homogenates. Another reason for reduced mortality in GC-treated BDL rats challenged with LPS may be attenuation of massive perivascular hemorrhages observed in BDL rats challenged with LPS. An intriguing observation was lack of effect of GC treatment on neutrophil recruitment indicated by similar MPO levels in lung homogenates of various groups. Although neutrophils have been linked to increased inflammation, tissue damage and mortality, the cytokines such as IL- $1 \beta$ can directly induce shock and mortality [32,39]. We do believe that additional experiments focusing on the role of individual cytokine such as IL- $1 \beta$ and TNF- $\alpha$ through their blockade or the use of specific gene knockout mice will shed more light on the mechanisms of this inflammatory process. Taken together, these data show that PIM depletion leading to reduced concentrations or intracellular retention of IL-1 $\beta$, TNF- $\alpha$ and IL-10 results in the beneficial effects.

These new data demonstrate a critical role of recruited PIMs in endotoxin-induced mortality in a BDL rats. It is striking that depletion of a single inflammatory cell results in remarkable reduction in key inflammatory cytokines, inhibition of lung inflammation and mortality. Although significant effort is invested in therapeutic targeting of single cytokines, these data show the attraction of therapeutic targeting of a cell such as PIMs.

\section{Competing interests}

The authors declare that they have no competing interests.

\section{Authors' contributions}

SSG conducted the experiments, analysed the data and participated in the preparation of the first draft of the manuscript, SSS performed RTPCR and helped with ELISA, KSJ assisted in surgeries and MPO assay, SC helped with immuno-electron microscopy, TD is helped in supervision of the project and read the manuscript and $\mathrm{BS}$ is the principal investigator who participated in the study design, data analyses and manuscript preparation.

\section{Acknowledgements}

The work was supported through grants from Natural Sciences and Engineering Research Council of Canada and Equine Health Research Fund of Western College of Veterinary Medicine to Dr. Baljit Singh. Dr. Gill and Dr. Janardhan were supported through Graduate Fellowships from Interprovincial Fund of Western College of Veterinary Medicine.

\section{References}

I. Fallon MB, Abrams GA, McGrath JW, Hou Z, Luo B: Common bile duct ligation in the rat: a model of intrapulmonary vasodilatation and hepatopulmonary syndrome. Am J Physiol 1997, 272(4 Pt I):G779-G784.

2. Luo B, Liu L, Tang L, Zhang J, Ling Y, Fallon MB: ET-I and TNFalpha in HPS: analysis in prehepatic portal hypertension and biliary and nonbiliary cirrhosis in rats. Am J Physiol Gastrointest Liver Physiol 2004, 286(2):G294-G303.

3. Ling Y, Zhang J, Luo B, Song D, Liu L, Tang L, Stockard CR, Grizzle $W E$, Ku DD, Fallon MB: The role of endothelin-I and the endothelin $B$ receptor in the pathogenesis of hepatopulmonary syndrome in the rat. Hepatology 2004, 39(6): I593-I602.

4. Rabiller A, Nunes H, Lebrec D, Tazi KA, Wartski M, Dulmet E, Libert JM, Mougeot C, Moreau R, Mazmanian M, Humbert M, Hervé P: Prevention of gram-negative translocation reduces the severity of hepatopulmonary syndrome. Am J Respir Crit Care Med 2002, I 66(4):514-5I7.

5. Chang SW, Ohara N: Chronic biliary obsrtuction induces pulmonary intravascular phagocytosis and endotoxin sensitivity in rats. Journal of Clinical Investigation 1994, 94:2009-2019.

6. Staub NC: Pulmonary intravascular macrophages. AnnRevPhysiol 1994, 56:47-67.

7. Warner AE, Brain JD: The cell biology and pathogenic role of pulmonary intravascular macrophages. Am J Physiol 1990, 258(2 Pt I): LI - I2.

8. Frevert $C W$, Warner $A E$, Kobzik L: Defective pulmonary recruitment of neutrophils in a rat model of endotoxemia. $A m J$ Respir Cell Mol Biol I994, I I(6):7 I6-723.

9. Brain JD, Molina RM, Decamp MM, Warner AE: Pulmonary intravascular macrophages: their contribution to the mononuclear phagocyte system in 13 species. Am J Physiol 1999, 276(I Pt I):LI46-LI54.

10. Warner AE, Decamp MM, Molina RM, Brain JD: Pulmonary removal of circulating endotoxin results in acute lung injury in sheep. Lab Invest 1988, 59(2):219-230.

II. Singh B, Pearce JW, Gamage LN, Janardhan K, Caldwell S: Depletion of pulmonary intravascular macrophages inhibits acute lung inflammation. AJP - Lung Cellular and Molecular Physiology 2004, 286(2):L363-L372. 
12. Decamp MM, Warner AE, Molina RM, Brain JD: Hepatic versus pulmonary uptake of particles injected into the portal circulation in sheep. Am Rev Respir Dis 1992, I 46(I):224-23I.

13. Sone Y, Serikov VB, Staub NC: Intravascular macrophage depletion attenuates endotoxin lung injury in anesthetized sheep. J Appl Physiol 1999, 87(4): I 354-I359.

14. Parbhakar OP, Duke T, Townsend HG, Singh B: Depletion of pulmonary intravascular macrophages partially inhibits lipopolysaccharide-induced lung inflammation in horses. Vet Res 2005, 36(4):557-569.

15. Charavaryamath C, Janardhan KS, Caldwell S, Singh B: Pulmonary intravascular monocytes/macrophages in a rat model of sepsis. AnatRecA DiscovMol Cell EvolBiol 2006, 288: I 259- I 27 I.

16. Singh B, Doane KJ, Niehaus GD: Ultrastructural and cytochemical evaluation of sepsis-induced changes in the rat pulmonary intravascular mononuclear phagocytes. I Anat 1998, | 92(Pt I): | 3-23.

17. Schneider T, Issekutz AC: Quantitation of eosinophil and neutrophil infiltration into rat lung by specific assays for eosinophil peroxidase and myeloperoxidase. Application in a Brown Norway rat model of allergic pulmonary inflammation. J Immunol Methods 1996, I98(I): I-I4.

18. Sztrymf B, Rabiller A, Nunes $H$, Savale L, Lebrec D, Le Pape A, de Montpreville V, Mazmanian M, Humbert M, Herve P: Prevention of hepatopulmonary syndrome and hyperdynamic state by pentoxyfylline in cirrhotic rats. Eur Respir J 2004, 23(5):752-758.

19. Nunes H, Lebrec D, Mazmanian M, Capron F, Heller J, Tazi KA, Zerbib E, Dulmet E, Moreau R, Dinh-Xuan AT, Simonneau G, Hervé $P$ : Role of nitric oxide in hepatopulmonary syndrome in cirrhotic rats. Am J Respir Crit Care Med 200I, I 64(5):879-885.

20. Singh B, Atwal OS: Ultrastructural and immunocytochemical study of the pulmonary intravascular macrophages of Escherichia coli lipopolysaccharide-treated sheep. Anat Rec 1997, 247(2):2|4-224.

21. de la Concha-Bermejillo A, Singh B, Whitney MS, Bazer FW: Acutephase proteins and hematologic values in ovine lentivirusinfected lambs treated with recombinant ovine IFN-tau. Interferon Cytokine Res 2000, 20:4 I-53.

22. Brown AP, Harkema JR, Schultze AE, Roth RA, Ganey PE: Gadolinium chloride pretreatment protects against hepatic injury but predisposes the lungs to alveolitis after lipopolysaccharide administration. Shock $1997,7(3): 186-192$.

23. Kim SG, Choi SH: Gadolinium chloride inhibition of rat hepatic microsomal epoxide hydrolase and glutathione S-transferase gene expression. Drug Metab Dispos 1997, 25(1 2): | $416-1423$.

24. Singh B, de la Concha-Bermejillo A: Gadolinium chloride removes pulmonary intravascular macrophages and curtails the degree of ovine lentivirus-induced lymphoid interstitial pneumonia. Int J Exp Pathol 1998, 79(3): I51-162.

25. Parbhakar OP, Duke T, Townsend HG, Singh B: Immunophenotypic characterization and depletion of pulmonary intravascular macrophages of horses. Vet Res 2004, 35(I):39-5I.

26. Pendino KJ, Meidhof TM, Heck DE, Laskin JD, Laskin DL: Inhibition of macrophages with gadolinium chloride abrogates ozoneinduced pulmonary injury and inflammatory mediator production. Am J Respir Cell Mol Biol 1995, I3(2): I25-I32.

27. Dinarello CA: Proinflammatory and anti-inflammatory cytokines as mediators in the pathogenesis of septic shock. Chest 1997, I I 2:S321-S329.

28. Nomura F, Akashi S, Sakao Y, Sato S, Kawai T, Matsumoto M, Nakanishi $\mathrm{K}$, Kimoto M, Miyake K, Takeda K, Akira S: Cutting edge: Endotoxin tolerance in mouse peritoneal macrophages correlates with down-regulation of surface Toll-like receptor 4 expression. J Immunol 2000, I 64( I):3476-3479.

29. Hoshino K, Takeuchi O, Kawai T, Sanjo H, Ogawa T, Takeda Y, Takeda K, Akira S: Cutting edge: Toll-like receptor 4 (TLR4)deficient mice are hyporesponsive to lipopolysaccharide: evidence for TLR4 as the Lps gene product. The Journal of Immunology 1999, I 62(7):3749-3752.

30. Singh SS, Janardhan KS, Parbhakar O, Caldwell S, Appleyard G, Singh $\mathrm{B}$ : Expression of toll-like receptor $\mathbf{4}$ and $\mathbf{2}$ in horse lungs. Vet Res 2006, 37(4):54|-55I.

31. Tumgor G, Berdeli A, Arikan C, Levent E, Aydogdu S: Mcp-I, eNOS, tPA and PAI-I Gene Polymorphism and Correlation of Gen- otypes and Phenotypes in Hepatopulmonary Syndrome. Dig Dis Sci 2008, 53(5): | 345-I35|.

32. Dinarello CA: The interleukin-I family: 10 years of discovery. FASEB ] | 994, 8( I 5): | 3 |4- | 325.

33. Creasey AA, Stevens P, Kenney J, Allison AC, Warren K, Catlett R, Hinshaw L, Taylor FB Jr: Endotoxin and cytokine profile in plasma of baboons challenged with lethal and sublethal Escherichia coli. Circ Shock I991, 33(2):84-91.

34. Welbourn CR, Young Y: Endotoxin, septic shock and acute lung injury: neutrophils, macrophages and inflammatory mediators. BrJ Surg 1992, 79(1 0):998-1003.

35. Razavi HM, Wang IF, Weicker S, Rohan M, Law C, McCormack DG Mehta S: Pulmonary neutrophil infiltration in murine sepsis: role of inducible nitric oxide synthase. Am J RespirCrit Care Med 2004, I 70(3):227-233.

36. Gao H, Leaver SK, Burke-Gaffney A, Finney SJ: Severe sepsis and Toll-like receptors. Semin Immunopathol 2008, 30(I):29-40.

37. Lentsch $A B$, Shanley TP, Sarma $V$, Ward $P A$ : In vivo suppression of NF- $k$ B and preservation of I $k$ B $\ddagger$ by interleukin- $I 0$ and interleukin- I3. Journal of Clinical Investigation 1997, 100:2443-2448.

38. Cho HY, Morgan DL, Bauer AK, Kleeberger SR: Signal transduction pathways of tumor necrosis factor - mediated lung injury induced by ozone in mice. AmJRespirCrit Care Med 2007, I 75(8):829-839.

39. Fischer E, Marano MA, van Zee KJ, Rock CS, Hawes AS, Thompson WA, DeForge LE, Kenney JS, Remick DG, Bloedow DC: Interleukin-I receptor blockade improves survival and hemodynamics performance in Escherichia coli septic shock, but fails to alter host responses to sublethal endotoxemia. Journal of Clinical Investigation 1992, 89: I55 I-I557.
Publish with Biomed Central and every scientist can read your work free of charge

"BioMed Central will be the most significant development for disseminating the results of biomedical research in our lifetime. "

Sir Paul Nurse, Cancer Research UK

Your research papers will be:

- available free of charge to the entire biomedical community

- peer reviewed and published immediately upon acceptance

- cited in PubMed and archived on PubMed Central

- yours - you keep the copyright 